\title{
Re-engineering of Georgian Railways and optimizing their project management
}

Davit JAPARIDZE, Boris GITOLENDIA

DOI: 10.30464/jmee.2019.3.2.109

Cite this article as:

Japaridze D., Gitolendia B. Re-engineering of Georgian Railways and optimizing their project management. Journal of Mechanical and Energy Engineering, Vol. 3(43), No. 2, 2019, pp. 109-114.

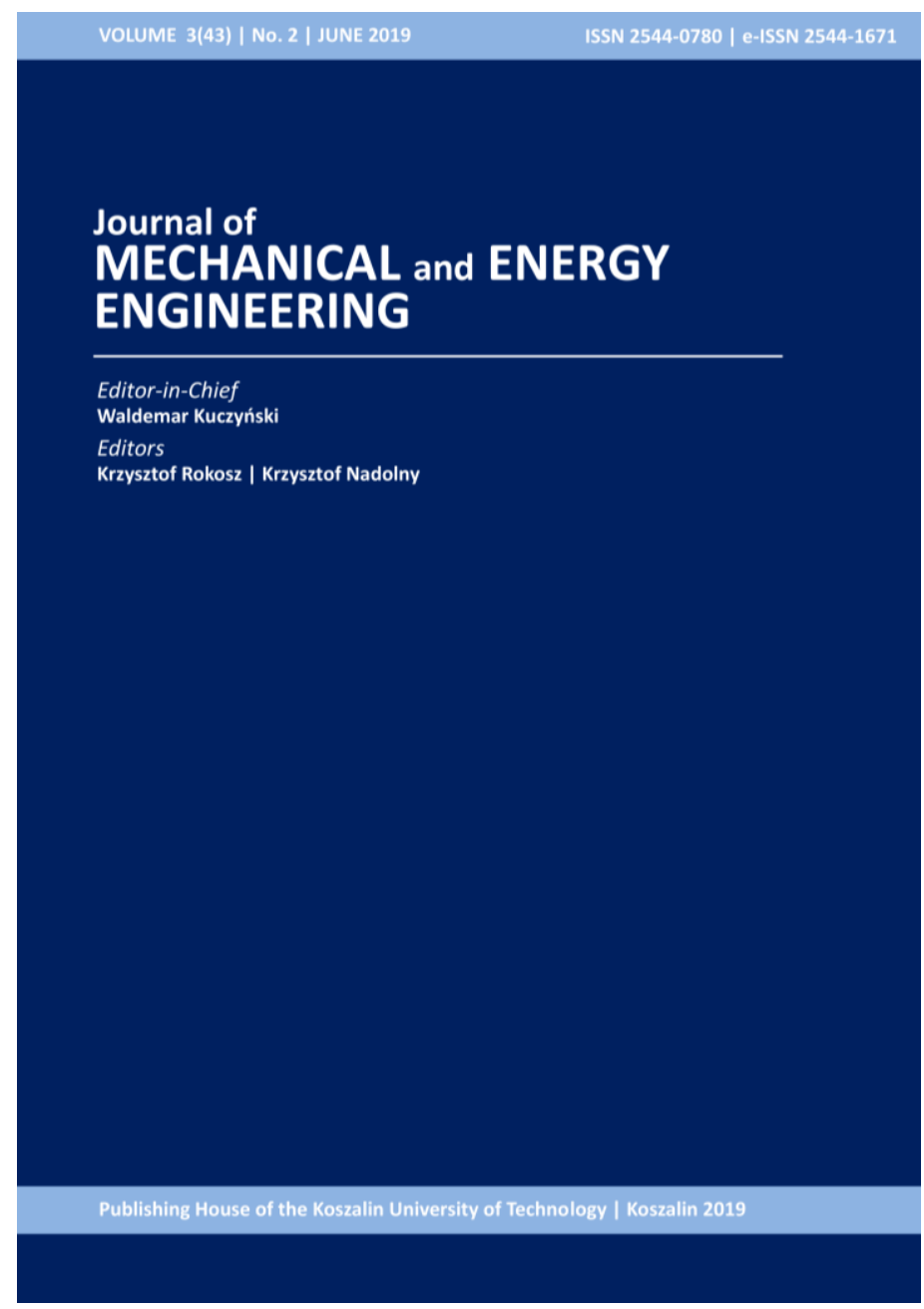

Journal of Mechanical and Energy

Engineering

Website: jmee.tu.koszalin.pl

ISSN (Print): 2544-0780

ISSN (Online): 2544-1671

Volume: 3(43)

Number: 2

Year: 2019

Pages: 109-114

Article Info:

Received 11 April 2019

Accepted 17 May 2019

\section{Open Access}

This article is distributed under the terms of the Creative Commons Attribution 4.0 (CC BY 4.0) International License (http://creativecommons.org/licenses/by/4.0/), which permits unrestricted use, distribution, and reproduction in any medium, provided you give appropriate credit to the original author(s) and the source, provide a link to the Creative Commons license, and indicate if changes were made. 


\title{
RE-ENGINEERING OF GEORGIAN RAILWAYS AND OPTIMIZING THEIR PROJECT MANAGEMENT
}

\author{
Davit JAPARIDZE $^{1 *}$, Boris GITOLENDIA ${ }^{2}$ \\ ${ }^{1 *}$ Georgian Technical University, Faculty of Transportation and Mechanical Engineering, Department of \\ Transportation and Mechanical Engineering Management, Kostava St. 68, Building 1, Tbilisi, Georgia, \\ e-mail: d_japaridze@gtu.ge \\ ${ }^{2}$ Georgian Technical University, Faculty of Transportation and Mechanical Engineering, Kostava St. 68 , \\ Building 1, Tbilisi, Georgia
}

(Received 11 April 2019, Accepted 17 May 2019)

\begin{abstract}
This article discusses the processes of current re-engineering of the Georgian Railway. Georgian Railway was founded in 1865 and its operations started in 1871. It sits on the shortest route between Europe and Central Asia. When we analyze the re-engineering issues of a particular country, we conclude that there is no general recipe on the process of re-engineering in the railway of any country. Decisions which were made in different countries, despite the fact that the approaches to the process of re-engineering were different, the world experience has demonstrated some similar actions that are common for these processes. I would like to present the recommendations and approaches which show the common actions that are useful for all railway administration. The article is built on theoretical and practical issues that will help us to learn about the project management of re-engineering and give an idea how to use it in our future career.
\end{abstract}

Keywords: Railway Transport, Re-Engineering, Management, Georgian Railway

\section{INTRODUCTION}

Railway transport plays a vital role in the world economy. It is at the heart of distribution of trade flows, which transports not only a cargo, but also people. It also creates jobs and is an effective mechanism for economic growth. Railway transport connects people with each other; it is important for both society and quality of life [1].

The re-engineering projects and the optimization of their management has enormous potential to revive of the railway system, the research plan of reengineering aims to improve the financial and technical structure of railway organization, it promotes the increase in its sustainability, efficiency and security. That's why it is necessary to continue reengineering, because Georgia and not only Georgia have to provide progressive technological achievements in railway transport, the railway should become a part of the global supply network, as a reliable partner for countries and economic regions, in a highly competitive globalized economy [2].
In general there is no purpose to know how to operate a railway company during the re-engineering process. Since the political status, financial status, management culture, product philosophy, employer and employee relationship, technological processes are different in each country.

\section{MATERIALS AND METHODS}

From the beginning of the 70s, around the world, the railway administrations were trying hard to solve the problems arising in the process of re-engineering. My lecture course discusses the processes of current re-engineering of the Georgian Railway, the lecture is built on theoretical and practical issues that will help us to learn about the project management of reengineering and give an idea how to use it in our future career.

As it is known, there are three types of organizational structural models in the railway organizations, these are the:

- vertically integrated model;

- vertically divided model;

- market-oriented model. 


\subsection{Vertically integrated model}

This is a classical organizational structure that can be evaluated as a centralized and hierarchical structure. Although this model has horizontaly specialized divisions (railroads, finances, marketing, human resources, etc.) between vertical structures and also geographically different positioning stations, the functions of the railway structure are still traditional in their infrastructure, operations management, marketing and other areas of centralised control. This model does not meet the requirements of the modern market and is focused only on production. In other words, all railway transportation in the country is organized within a single structure, management center and accounting system, and the income and expenses can not be separated. Any other function should be implemented for all markets and activities such as infrastructure, passenger transfers and cargo of.

The strengh of this structure is that it gives management the advantage of the ability full planning.

While the weakness is that it does not respond to different market segment requirements and reduces productivity.

\subsection{Vertically divided model}

In contrast to the integrated model, this model is divided into two structures, the first is the operating system, which leads the cargo and passenger transport operations, and the second is infrastructure that realizes the operating system, which serves the purpose of passenger and cargo transportation. The main goal of this model is to pave the way for different users and to promote competitiveness.

The positive side of this model is that it enables many users to get involved in passenger and cargo transportation, which increases competitiveness.

The negative side is that they encounter difficulties to create a flexible train schedule, plan investments, and thus it limits their ability to provide high value custmer service and cost of delivery.

In this model only the infrastructure and operational work is separated and it does not consider sufficient issues of reorganization and thus does not provide market-oriented service development.

\subsection{Market-oriented model}

This model is divided into railway companies such as trucks, passenger, infrastructure, locomotives depots, carpentry refineries, etc. The goal of each of them is to maximize its customer satisfaction. That's why the priority of the vertical integration division is a structural method that demonstrates and develops the needs for each of them on the market. At this model, all working units have the responsibility of their own incomes and outgoings, with independent accounting and profit purposes. In the early 90s, this model has been improved and refined. Infrastructure, transportation and rolling structures were divided into different units.
This model was first used in England in the years 1980-1994, and After England, many European countries moved to this model, such as Spain, Holland and Germany and began to divide the working units.

The strongest segment of this model is the promotion of the commercial market, which ensures easy access to service delivery, reduces bureaucracy, ensures expenditure and subversion transparency.

The weaknesses relate to the management of financial, legal and technological operations. Especially when it comes to their separation process [4].

Before starting the review of the Georgian Railway, according to the adove mentioned models, I would like to introduce briefly DB Germany and SNCF French Railways, they have already experienced re-engineering and have established the most successful organizational structures in Europe.

\section{German Railway (DB) „Deutsche Bahn“Deutsche Bahn}

The German Railway is a private joint-stock company (AG), with the Federal Republic of Germany being its single shareholder. It is headquartered in Berlin, Since January 1, 1994, the German government has concentrated on railway reengineering, uniting the railways of West and East Germany and formed the German Railway, whose entire capital belongs to the state. On the basis of the EU N 91/441 Directive, the infrastructure and operating system were separated and the lines were opened to third parties with equal rights, i.e it became a market-oriented model. Estabilshed subsidiary companies, such as DB Schenker, DB Cargo, DB Regio, DB Netz, Arriva. All of them are independent companies and serve different segments of the railway market.

In addition, two independent public bodies, Federal Railway Authority (EBA) and Federal Bureau Assets (BEV) were estabilished.

The Federal Railways Authorities has numerous functions, which includes: approving the Federal Railway Plans, granting permission to authorize the rolling stock and railway infrastructure to fund the federal government's funds in the railway sector, as well as protection the passengers' rights. It is a part of the federal transport administration.

Federal Bureau's assets are administered by federal transport and finance ministries. It is responsible for the retirement of former employees and manages the health insurance fund.

The German Railway has been in profit since 1995 and cargo transportation has increased by $60 \%$. According to the data of 2016, its total income is 48.50 billion euros. It is the sixth largest in the world and its rail network is $43,468 \mathrm{~km}$ [4]. 
French Railway (SNCF, „French National Railway Company")

The French National Railways was founded in 1938 and (SNCF) is a state-owned enterprise with commercial status. It has an independent organizational and legal form as well as its business and financial activities, but under government control. Infrastructure and operations are separated organizationally. SNCF is an operator organization which has its subsidiaries such as Ouigo, OUIBUS, Thalys, iDTGV and others. While RFF - is an infrastructure organization. All infrastructural properties of railway transport were transferred to the "RFF"- (except stations) SNCF manages railway transportation and its operation, it is paying the money to the "RFF" for railway lines service. Whose costs are determined by the use of railway lines. The government is responsible for the management and improvement of infrastructure.

145,000 employees are working in the French Railway and its total length is $32000 \mathrm{~km}$. [5].

\section{Georgian Railway GR “Georgian Raiway"}

Georgian Railway was founded in 1865 and its operations started in 1871 . It sits on the shortest route between Europe and Central Asia. (Fig. 1)

Its technical characteristics are the following: The width of the track is $1520 \mathrm{~mm}$, max. slope $37 \%$, min. radius $160 \mathrm{~m}$, tunnels 45 , bridges 1714 , expanded length $1879 \mathrm{~km}$, operational length $1575 \mathrm{~km}$, twotrack lines $290 \mathrm{~km}$, single-track lines $1285 \mathrm{~km}$, narrow- tracks $37 \mathrm{~km}$, lifting type permanent electricity $3000-3500 \mathrm{~V}$. The total number of stations is 109 units that are divided into five categories (Tab. 1).
After Georgia became independent and separate from the Soviet Union it became Georgian Railway and its assets were formed into the new $100 \%$ government owned company. After that, it was established as the Georgian Railway Ltd. In this period, its organizational structure can be compared to the vertically integrated model. [6].

Tab. 1. JSC "Georgian Railway" stations according to categories

\begin{tabular}{cccccc}
\hline \multirow{2}{N}{ o } & $\begin{array}{c}\text { I Class } \\
\text { Station }\end{array}$ & $\begin{array}{c}\text { II Class } \\
\text { Station }\end{array}$ & $\begin{array}{c}\text { III Class } \\
\text { Station }\end{array}$ & $\begin{array}{c}\text { VI Class } \\
\text { Station }\end{array}$ & Post \\
\hline Total & 10 & 7 & 30 & 54 & 8 \\
\hline \multicolumn{3}{c}{ Totally } & & 109 & \\
\hline
\end{tabular}

In 2007, commenced panning and implementation of re-engineering projects of the Georgian Railway. "Georgian Railway" Ltd. was established as a joint stock company and $100 \%$ of its shares belonged and untill now belong to the state. The aim of the projects was the transformation of the vertically integrated model into a vertically divided model and in this respect a number of efforts were made.

Three branches were separated from the unified system:

- Georgian Railway Infrastructure Branch;

- Cargo transportation Branch;

- Passenger transport Branch.

Despite this, the Georgian Railways, nowadays, still can't satisfy the interests of society and the national economy (Fig. 2), (Fig. 3).

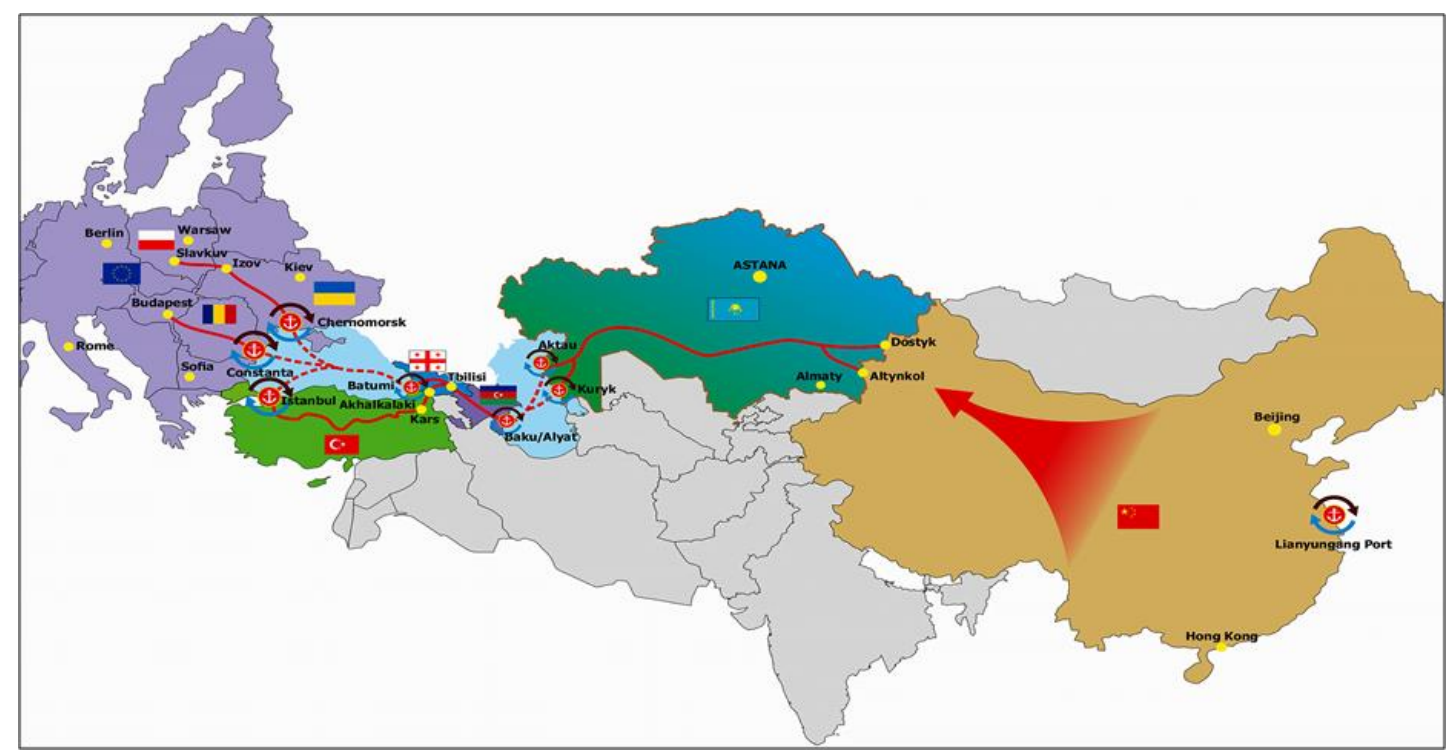

Fig. 1. Trans-Caspian International Transport Corridor 
Today's situation can be explained as follows:

- there is no open access to the third parties to the Georgian Railway sector;

- Georgian Railway is the only (monopoly) railway transport service provider in Georgia;

- Georgian Railway is a horizontally integrated transport company in different organisation structures;

- Georgian Railway does not have a market-oriented organizational structure;

- the Georgian Railway Cargo Department is obliged to compensate the loss of the passenger transportation service;

- there are no independent railway authorities taking into account the European Union legislation;

- there is no system of licensing for infrastructure managers and railway companies because the Georgian Railway is the only railway company [7].

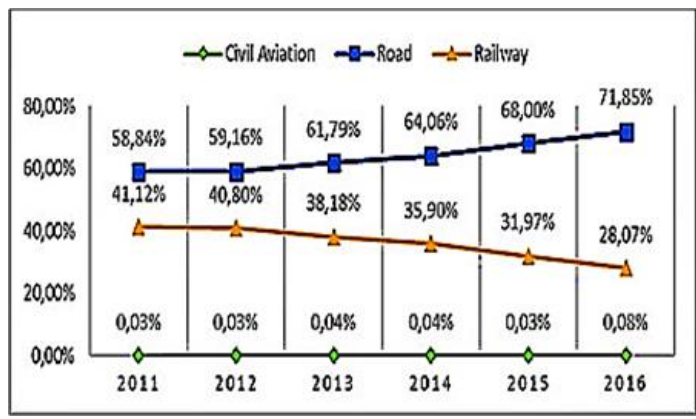

Fig. 2. Market share in Cargo Transportation (Mln. Tons)

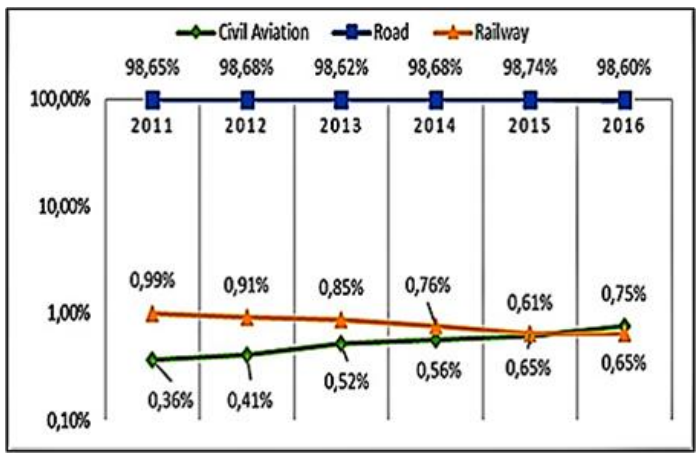

Fig. 3. Market share in Passenger Transportation

\section{RESULTS AND DISCUSSION}

As we can see, it is time and the need is great for the Georgian Railway to move on a market-oriented model.

A new type of railway is required. First of all, it should be a business, with such management which is independent and free to use, but is responsible for its mistakes. It has enough money to pay, which is free from the obligations taken from the past. Market forces must be put into effect in a manner that will lead to greater involvement of the private sector.
In this regard Georgia has implemented a number of measures, the first and most important was the signing of the Association Agreement on 27 June 2014, between the Parties representing Georgia, the European Union and the European Atomic Energy Community and their Member States.

Definition of EU Railway legistlation will lead to re-engineering of the whole railway sector of Georgia. It will change the "rules of the game" in this sector, which acts as a state monopolist, JSC Georgian Railway.

This document is based on the European approach to access to open market with the prerequisite of separation of infrastructure and operations. The main outcome will be the separation of infrastructure and operations to enable the private sector to work on the public infrastructure network and invest in the railway sector. In accordance with the EU directive 2012/34/EU [7].

The future manager of railway infrastructure must open its network for third-party railway operators to use it and compete in the railway network in nondiscriminatory and fair manner.

\subsection{Important explanations about the separation} of operations from infrastructure

1. The railway enterprise means any public or private venture whose main activity is transportation of cargoes and / or passengers by railway system to ensure transit.

2. Infrastructure Manager appoints any body or firm responsible for the functioning, maintenance and renewal of the railway network infrastructure, as well as the body responsible for its development as defined by the Member States in the General Policy of Financing and Infrastructure Funding.

3. Development of railway infrastructure means network planning, financial and investment planning, as well as building and renewing infrastructure.

4. Functioning of railway infrastructure - means arrangement of train rails, transport management and infrastructure.

5. Maintenance of technical ways of railway infrastructure means maintaining the state of the existing infrastructure and capacity.

6. Renovation of railway infrastructure implies a major change in infrastructure that will improve its overall work.

7. Improvement of railway infrastructure implies significant modifications of infrastructure, which will improve overall activities.

For the purpose of re-engineering of Georgian Railway, the new project principes and project frames should be defined and implemented, the next planning guide should be based on the accumulated experience in the European Union, which will study the major mistakes of re-engineering of the railway sector and also consider good examples. 


\section{First step}

Effective, competitive, environmental and safe transportation sectors should be a political liability and a national (better regional) transport strategy for all types of transport strategies, for which it is necessary to financing this strategy well.

\section{Second step}

Prepare an existing railway, which corresponds to the market.

This does not mean only the separation of infrastructure. This also implies the following measures:

- customer Orientation (sales teams, new products eg multimodalism, products delivered at home);

- improvement of personnel work (bonus systems, reduction of extra staff)

- creation of a new modern process (controlling, calculation of costs, asset management, lease trade), which will enable the existing operator to compete against newly created private railway companies,

- long-term financing on contract basis based on clearly indicated goals and required performance indicators in accordance with Directive 2012/34 / EU. Such measures are often neglected or forgotten in EU member states and AA countries. The existing state railway remained unattached and didn't meet the enviromental requirements when opening the market. This has created a lot of social problems for taxpayers.

\section{Third step}

Third step (Parallel to the second step): The development of the railway sector and the promotion of market should be adapted to new structures and systems in compliance with European regulations and regulations. People working on the newly created railway system should support, train and advice on legislative issues. Authors should also be clientoriented - their customers are both active and new operators - they should help them to prepare and get acquainted, explain the new spirit of the law and the new rules of the game in the railway sector.

\section{Market access - fourth step}

The competition starts and introduces private capital on the railway market, providing new technologies and additional products for attracting clients [3].

\section{CONCLUSIONS}

It seems that, when we analyze the re-engineering issues of a particular country, we conclude that there is no general recipe on the process of re-engineering in the railway of any country. Decisions which were made in different countries, despite the fact that the approaches to the process of re-engineering were different, the world experience has demonstrated some similar actions that are common for these processes. I would like to present the recommendations and approaches which show the common actions that are useful for all railway administration.

\subsection{Evaluation of reorganization studies}

First of all, the political and financial conditions of a particular country, management culture, technological education level and their growth potential, industrial philosophy, employer and employee relationship should evaluated and analyzed. On the first stage, after assisting this it is possible to implement the process of re-engineering.

\subsection{Renew Relationship with Government}

Railway is a public service. Therefore, the common idea lies in the fact that the railway should be able to independently conduct commercial activities. This means that new modern relations between the railway and the government should start. Terminate everyday political decisions and put on new agendas, to set new agreements, which will define the obligations of the Parties, it is necessary to regulate the limits of government power in matters such as the implementation of railway projects, goals and commercial issues, including financial and legal relationships, terms of payment of old debt etc.

\subsection{Focused on priority activities}

This circumstance implies the focus of railway activities only on transport services and its improvement. It is necessary to remove activities and assets that require additional effort and costs.

\subsection{Separation of the infrastructure and operations}

The main objective of separation of infrastructure and operations is to improve the conditions for attracting private user resources, to get a competitive market experience. They will be provided with the tariffs available and defining costs will be possible at least in advance, it will also facilitate the relationship with the customer.

\subsection{Reduce the number of extra staff and increase productivity}

One of the key factors of the successful operation of the railway is to carry out the right personnel policies, which involve the minimum personnel employment with the maximum result. The two main priorities of the process of rein-engineering are to reduce the number of full staff and increase productivity of each person. That's the key to success.

\subsection{Customer-oriented approach according to the market segment.}

The world experience shows that the shipping market is wide and it has many segments, which makes it difficult to provide customers with a complete range of services. Therefore, new approaches first of all should be identified which 
segment of the market will be served by the railway and the ways of transporting services which will meet the economic needs of target audience. With these approaches the Railway will be able to ship different cargoes of different markets, which in turn will be the most profitable for both sides.

\subsection{Free access to the railway network}

The most important in railway re-engineering is to provide free access to railway infrastructure for various operators. If till now, it was possible only for a public operator to use its railway network and made transportations with its electric locomotives and carriages, now, after the re-engineering process, railway infrastructure can be utilized by various private operators and subsidiaries after a certain amount of reimbursement, which in turn paved the way for the Intercontinental Network and International Operators, which are also the EU Directive.

These are general recommendations which should be taken into consideration for the railway administrations of all countries.

\section{References}

1. Tkeshelashvili G., (2018). Georgian Transport. Georgian Technical University, Tbilisi.

2. Japaridze D., (2012). The management of factors acting on the efficiency of investment and innovation projects at the railway transport and to its improvement. Georgian Technical University, Tbilisi.

3. Gabrielashvili G., Lashkhi I., Pataraia T., Imnaishvili A., (2010). Georgian Railway Problems and Perspectives. Open Society Georgia Foundation Presented A New Analytical Report On: "Georgian Railway: Problems And Perspectives" On February 12, At Tbilisi Marriott Hotel, pp. 13-20.

4. Müller A., (2014) Railway Market Analysis. Bundesnetzagentur. Tulpenfeld.

5. Bonnafous A., Crozet Y., Efficiency indicators of Railways in France (2014) The International Transport Forum: Efficiency in Railway Operations and Infrastructure Management. On 18-19 November International Energy Agency, Paris, France pp. 3-14.

6. Japaridze D., (2011). Ways of Georgian Railway Infrastructure Improvement. Journal of Transport and Machine building Vol. 22, No.10, pp 86-88.

7. Gitolendia B., (2018). About Compatibility of Georgian Railway and Related Infrastructure to European standards. ISSN2413-1032 Tbilisi, Georgia, 5-12 May Georgian Technical University № 5(33), Vol.1, pp 5963.

\section{Biographical notes}

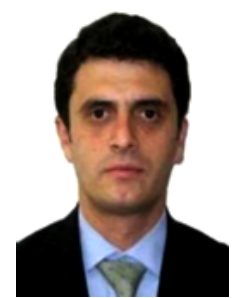

Davit Japaridze - Doctor of Business Administration, Assistant-Professor of Transportation and Mechanical Engineering Faculty at Georgian Technical University Participation in the international and local scientificresearch projects; Author of 12 Scientific Articles; Participant of 8 international and local Sciences and practical Conferences; 8 years of experience in EducationalMethodology and Academic activities; His scientific interests focus on problems concerning to Railroad transport and the other transport sector problems; The study of efficiency of investment and innovation projects in Mechanical Engineering; Innovation systems, Startup Development, educational especially the university projects.

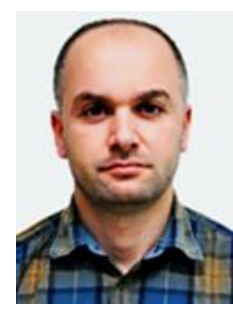

Boris Gitolendia - Doctor of Business Administration, Associated-Professor of Transportation and Mechanical Engineering Faculty at Georgian Technical University, Participation in the international and local scientificresearch projects; Author of 17 Scientific Articles; Participant of 30 international and local Sciences and practical Conferences; Co-editor and Author of 1 Manual Book and 1 Additional Manual Book. 10 years of experience in Educational-Methodology and Academic activities; His scientific interests focus on problems concerning Georgian transport and the transport sector problems; Trans-Caucasian Corridor; The study of Georgian transport-transit potential; The study of issues of the Association Agreement provided for "Deep and Comprehensive Free Trade Agreement" (DCFTA); Innovation systems, Startup Development, educational especially the university projects. 